\title{
ENTREVISTA DE JÚLIA NERY
} SOBRE A PECA O PLANTADOR DE MAUS A HAVER, CONCEDIDA aO PROJeto AUTOR POR AUTOR: A LITERATURA PORTUGUESA A LUZ DO TEATRO

http://dx.doi.org/10.11606/issn.2175-3180.v13i24p133-142*

Por Alleid Ribeiro Machado ${ }^{\mathrm{I}}$

Incluímos nesta sessão, uma contribuição de Júlia Nery ao Projeto Autor por Autor: a literatura portuguesa à luz do teatro. ${ }^{1}$ Trata-se de uma entrevista concedida entre os anos de 2001 e 2002, que diz respeito a questões relativas à peça O plantador de naus a haver (Asa, Porto, 1994). ${ }^{2}$

Júlia Nery é nascida em Lisboa. Desde a década de 80, a autora vem se destacando no cenário da literatura portuguesa com a publicação de

\footnotetext{
* Publicada originalmente na revista Desassossego, v. 2, n. 3, jun/2010:

https://www.revistas.usp.br/desassossego/issue/view/3941

DOI original: http://dx.doi.org/10.11606/issn.2175-3180.v2i3p174-182

I Universidade de São Paulo, São Paulo, Brasil.

1 A entrevista consta da dissertação de mestrado O plantador de naus a haver sob a óptica da intertextualidade, defendida em 2006, na Faculdade de Filosofia, Letras e Ciência Humanas da Universidade de São Paulo, sob orientação da $\operatorname{prof}^{\mathrm{a}} \mathrm{dr}^{\mathrm{a}}$ Flavia Maria Corradin.

2 Projeto idealizado e coordenado respectivamente pelos Prof. Drs. Francisco Maciel Silveira e Flavia Maria Corradin.
} 
peças de teatro, contos e romances, dos quais destacamos: Pouca terra... poucá terra (1984); Infantas de Portugal (1998); Aquário na gaiola (2008); O segredo perdido (2005); e Crônica de Brites (2008). A maior parte de sua produção gira em torno de temas ligados ao universo feminino, tema que está sendo amplamente estudado em nossa tese de doutorado desenvolvida junto ao Programa de Pós-graduação da FFLCH/USP: As personagens femininas de Júlia Nery: paradigmas e representações.

\section{SOBRE O PLANTADOR DE MAUS A HAVER, POR JÚLIA NERY}

ALLEID RIBEIRO MACHADO: Qual (quais) julga ser(em) a(s) força(s)motriz(es) de sua obra?

JÚLIA NERY: Refletindo sobre as possíveis respostas a esta pergunta, pois foram várias as "forças" que me impeliram a escrever O plantador de naus a haver, encontro uma que foi determinante e a mais motivadora: a figura de D. Dinis, enquanto homem de cultura para a cultura, de pensamento e ação, o "árbitro das Espanhas", como então era conhecido. A poesia, de D. Dinis a Pessoa, a construção de um reino que vai surgindo numa terra de pauis e lodaçais, semeando-se futuros já com o pensamento para além do mar, tudo isto me convocou à escrita do "Plantador...". Talvez por mergulhar nas raízes galaico portuguesas, com um raminho de árabe.

Amador, poeta, rei-lavrador, guerreiro, diplomata, marido quase impossível de uma santa, vivendo a saudade de uma esposa presente, mas ausente de si pela entrega mística ao amor divino, o grande rei D. Dinis não tem sido, como merecia, revisitado pela História. Pois que a palavra, também poética, de um texto dramático o faça reviver!

ARM: Como se dá seu processo de criação?

JN: Mais uma vez, o real se socorreu da imaginação criadora. Lecionando Literatura Portuguesa (a poesia trovadoresca) numa turma muito desinteressada, dava eu voltas à imaginação para descobrir maneiras de despertar os alunos para o prazer da leitura desta poesia. Dramatizei com eles algumas cantigas de amigo, e o poeta D. Dinis começou, quase por acaso, a impor-se-nos. Escrevi então um diálogo, embrião de um pequeno texto dramático de que ele era o protagonista. Resolvi documentar-me 
melhor sobre este homem para poder construir a personagem. Das livrarias passei às bibliotecas e arquivos em busca da mais variada documentação, tendo mesmo visto o testamento de D. Dinis na Torre do Tombo. Ao mesmo tempo em que a minha convivência com D. Dinis era tão excessiva que eu julgava pensar e sentir como ele, que a minha admiração por este rei poeta crescia, o diálogo inicial transformava-se no texto que agora é O plantador de naus a haver.

ARM: Considera o subsídio governamental e/ou privado indispensável para o florescimento do teatro?

JN: Penso que a questão é relativa às Companhias/Grupos de teatro e não aos criadores do texto dramático.

Quanto aos subsídios (governamentais ou privados) destinados a incrementar os espetáculos teatrais, a minha opinião baseia-se na realidade portuguesa, pois desconheço inteiramente a brasileira.

Como considero o teatro uma arte que, além de deleitar e emocionar é, eminentemente, formativa e libertadora, penso que os espetáculos de teatro têm de visar a melhor qualidade, tanto no plano estético como técnico o que obriga, entre outras coisas, a uma responsável e onerosa formação de todos os seus intervenientes. Assim sendo, julgo o subsídio (que não entendo como uma espécie de óbolo, mas antes como um investimento cultural) indispensável para o florescimento do bom teatro.

ARM: Concorda com o diagnóstico de Eça de Queiroz, em páginas de Uma campanha alegre, que "o português não tem gênio dramático; nunca o teve, mesmo as passadas gerações literárias, hoje clássicas. A Literatura de Teatro toda se reduz ao Frei Luís de Sousa"?

JN: Dizer que o português não tem gênio dramático é demasiado redutor, se bem que ele seja, reconhecidamente, maior lírico. Quanto à afirmação de Eça de Queirós, muito teatro se escreveu depois dele, pelo que não poderemos hoje concordar com Eça, dizendo que a Literatura de teatro se reduz ao Frei Luís de Sousa. 
ARM: Em sua opinião, o que levaria um Autor a manter diálogo intertextual com a obra de outrem? No seu caso, mais especificamente, o que a motivou a reunir várias cantigas de D. Dinis e de alguns outros expoentes do Período Trovadoresco e teatralizá-las?

JN: Como qualquer outro diálogo, o intertextual enriquece e estimula ao provocar a resposta, abrindo novas perspectivas e libertando a criatividade.

A poesia trovadoresca, para mim, especialmente a de D. Dinis, é uma espécie de jóia da coroa da lírica portuguesa e que muitos poucos conhecem. Teatralizá-la é partilhar de uma forma mais viva que a simples leitura, o ritmo da bailada, a musicalidade da paralelística e da alba, a dramaticidade que a caracteriza, especialmente a da tenção, a malícia da poesia erótica e satírica

Teatralizar as cantigas de D. Dinis foi uma das maneiras de o revelar e de criar empatia por este rei-poeta.

Reconheço agora que, subjacente, haverá também essa faceta saudosista de mostrar algum do capital cultural amealhado, para que ele não se limite a ficar guardado no fundo das arcas avoengas, mas possa ser movimentado e dar lucros no futuro.

ARM: Como explica a tendência de a dramaturgia portuguesa vir desde o Romantismo repensando a História, dramatizando vida e obra de autores, figuras ou lances fundamentais do passado?

$J N$ : Fazendo, mental e rapidamente, uma retrospectiva do teatro português, tenho de reconhecer que muitos autores dramáticos se inspiram em fatos e vultos da História nacional, o mais das vezes numa perspectiva saudosista.

Como explicar esta tendência? Terá ela a ver com o fato de sermos um povo com um passado tão rico que sobe pelo presente como a trepadeira que enfraquece o ramo a que se agarra? Ou nascerá desta nostalgia que nos é própria e que busca no que passou a força para o que há-de ser?

Julgo, no entanto, que a tendência de repensar e interrogar a História dará bom fruto. 
ARM: Sem dúvida o drama histórico (de matiz romântico e patrioteiro) se diferencia daquilo que José Oliveira Barata chama de teatro da História (de matriz piscatoriana e brechtiana). No caso do teatro da História, o distanciamento, estranhamento pretérito, serve para revelar as mazelas do presente. Ou seja, perspectiva-se o passado como história do presente. Uma tal óptica implica que o espectador ou leitor esteja devidamente informado acerca do fato pretérito, que está sendo tratado como alegoria ou símbolo do presente, para que possa fazer as ilações e paralelismos devidos. No caso de o público não ter tais informações históricas, como estrategicamente se lhe desperta essa consciência? O didatismo de um narrador-comentador (ou de vários narradores/personagens) não pode prejudicar a ação, o conflito, mola-mestre de um texto dramático?

JN: Nestes casos, narrador /comentador /personagem são um mal necessário Penso que o didatismo que assumem prejudica de algum modo a ação, o conflito. $\mathrm{O}$ dramaturgo, consciente disso desde o primeiro momento da escrita do texto, terá de utilizar processos para que prejudique o menos possível.

ARM: D. Dinis logrou ser para a Literatura Portuguesa um dos mais fecundos trovadores portugueses, como Mecenas proporcionou um intenso período de efervescência cultural, contribuindo, a exemplo de seu avô, Afonso X, para o florescimento cultural de uma sociedade agrícola e feudal, trazendo a Portugal sábios e intelectuais. Qual o sentido da releitura de sua vida e obra no campo cultural de hoje?

JN: O campo cultural, no caso português, é hoje mais alargado. Neste contexto faz todo o sentido a releitura de vidas e obras que tenham afirmado a cultura portuguesa.

D. Dinis governou um povo que respeitava (sou rei da melhor e mais leal gente que possa ter senhor, católico ou pagão), em favor do qual procurou estabelecer uma maior justiça social com a sua política de distribuição da terra. Fomentou as artes e a diplomacia, sendo chamado como "árbitro" nos conflitos externos, pela sua reconhecida sabedoria, honestidade e justiça.

Trazer à cena D. Dinis é dar testemunho de que as sociedades governadas por poetas florescem, usufruindo de uma efervescência 
cultural que corresponde a períodos históricos de maior acalmia e de progresso.

ARM: Qual foi a sua intenção ao estabelecer um plano paralelo entre a vida de D. Dinis (que representava naquele momento a Nobreza) e a do Lavrador (representante da terra, do campo)? Por que o Lavrador ganha uma dimensão tão importante como narrador principal?

JN: Esta pergunta divide-se em duas questões que são também duas linhas dramatúrgicas importantes de O Plantador de Naus a Haver, a que tentarei responder separadamente:

Não é apenas por terem nascido à mesma hora e porque o Lavrador diz reconheci D. Dinis como se me mirasse nas águas do Guadiana que podemos estabelecer um paralelo entre estes dois homens Para uma melhor compreensão é muito importante o momento da investidura em que o Lavrador se lava dos pecados pelo suor do trabalho, que mortifica mas liberta, e D. Dinis, iniciante, se lava das vaidades mundanais pelo banho ritual que "aprisiona" o cavaleiro aos juramentos a que o obriga.

O grande tem o poder de governar os outros, mas menos poder sobre o governo da sua própria vida.

Não é por acaso que o lavrador vai contando a sua história, e é através desta narrativa que compreendemos que um rei, tal como um simples lavrador, tem de limpar o reino das ervas daninhas, mas com muito maior esforço.

É ainda pelas palavras do lavrador que se vão desenhando ao longo da peça os percursos paralelos de um poderoso e de um vassalo: "Riquezas de rei e de pobre não se medem pelo mesmo alqueire; só os sofrimentos. Os meus foram alegrias comparados com os dele."

Rei e Lavrador têm na investidura a visão da morte, momento único em que para os dois haverá igualdade entre o Lavrador. "Olhei a terra que escancarada me esperava e pensei na morte - e o seu Rei - Teu corpo à terra voltará."

Além de narrador principal, informante sobre a história de outro personagem (D. Dinis), o Lavrador é mais comentador que narrador e tem múltiplas funções.

Se o Lavrador é, por um lado, uma projeção de D. Dinis, a sua palavra do Lavrador exprime a crítica contra o poder, mas o mais 
interessante é ser pela sua boca que sabemos dessa espécie de cumplicidade entre o rei e o seu povo: entre nós e o rei um pacto que não foi preciso selar: "a terra a quem a trabalha". E este slogan moderno dito por um lavrador medieval provoca um efeito de distanciação.

Ele comenta, duvida, interpreta à luz de uma mentalidade ora prosaica ora poética, ironiza, conclui sobre os atos ou intenções de D. Dinis. Ao interpretá-lo, de tal maneira o faz que acaba por interpelá-lo (no monólogo do rei) como se fora uma das vozes da sua consciência.

A despeito da sua atitude crítica, o Lavrador humaniza o nosso olhar sobre o rei, aproximando-o da afetividade do espectador, empregando uma linguagem alegórica que retira os símbolos da realidade própria de um homem que trabalha a terra.

Do comentário crítico à interpretação, às vezes maldosa, dos atos do rei, O Lavrador chega a uma espécie de consciência moral de D. Dinis, exortando-o a enfrentar as suas fragilidades e a agir.

Mas é, afinal, pela voz do Lavrador que nos fica um retrato mais completo de D. Dinis. Ao interpretá-lo é como se o lavrador o encarnasse.

ARM: Amiúde a reconstituição do Ritual da Investidura de Cavaleiro na Ordem da Cavalaria reafirma a importância fundamental dada à profissão das armas naquele contexto histórico. Paralelamente, este ritual medievo ganhou novas proporções em sua obra quando veicula a idéia de que o homem simples, ou seja, não pertencente à nobreza, pode, à exemplo do 'cavaleiro', vir a ser purificado pelo trabalho. Qual foi a sua intenção ao estabelecer este paralelo?

JN: A "investidura do povo" terá de consumar-se nos rituais próprios da sua condição.

D. Dinis chamava aos lavradores os nervos da terra. Esta metaforização enobrece tanto o Lavrador quanto o mais alto epíteto da nobreza. Ao criar um momento paralelo de investidura para os dois, a autora pretendeu relembrar que sem os homens que trabalham nenhum rei terá um grande reino, nem se faz grande um povo.

Ao estabelecer um paralelo entre o rei e o lavrador a autora pretendeu dizer que um não pode existir sem o outro. Que têm ambos de servir-se, compreender-se e amar-se. 
ARM: Embora o Lavrador reconheça a bondade do Rei, seu discurso as vezes torna-se crítico e há passagens que a fragilidade humana de D. Dinis é bem nítida. Esses recursos somados ao espaço temporal em que se passa a cena seriam uma tentativa de não fazer de D. Dinis um herói inverossímil?

JN: O "meu" D. Dinis foi construído, ou melhor, revelado, de maneira a ser verdadeiro, verossímil. Como todo o comum dos mortais, as suas contradições entram em conflito.

Só um ciúme violento levaria um homem douto e sensível a mandar queimar o pajem da sua rainha. Como qualquer homem que viva um casamento abstêmio e com sete anos de esterilidade, este rei quer ter a prova da sua virilidade, o que faz dele um amador insaciável. Como qualquer pai, ele quer ser amado e justo com os filhos e quantas vezes as circunstâncias o fazem duvidar de que o seja. Como qualquer rei, ele quer a paz e o melhor para o seu reino, mas nem sempre as suas ações podem ser conformes a este desidério. Como qualquer homem, D. Dinis sofre, mas enfrenta as suas fragilidades.

Espero que o leitor (espectador) sinta o humaníssimo coração deste poeta que teve, tantas vezes, de reconciliar em si as necessidades e as pulsões contraditórias de homem, rei e pai.

ARM: Sendo o MOMO uma pequena farsa popular o que sugere essa encenação como recurso dentro da peça teatral?

JN: O MOMO assume, tal como o Lavrador o vai fazendo ao longo da peça, a função de nos "contar" criticamente o rei, mas além desta tem outras funções. Uma delas é o fazer parte da reconstituição do contexto cultural da corte de D. Dinis; outra é criar um momento de grande tensão (durante o momo são mimados os amores do rei), com o qual acaba o $2^{\underline{o}}$ ato.

O Momo tem ainda um momento importante, pretexto para a distanciação, introduzida pela chegada à cena da "nova arte de trovar" que é a voz de Fernando Pessoa.

ARM: As diversas Cantigas de Amor de D. Dinis elencadas na obra, traduziriam a consciência aguda do drama interior vivido pelo Rei, devido a inacessibilidade de uma Rainha tal qual a "Senhor" das cantigas de 
amor? Nesse momento, na sua opinião, o homem D. Dinis é o Trovador e sua poesia portanto o extrato dessa incorrespondência e/ou inacessibilidade?

JN: Podemos dizer que quase todas as cantigas de D. Dinis elencadas na obra, mesmo as que ele dirige a outras mulheres, têm muita relação com o drama interior vivido pelo homem que não pode ter ciúme do amor de sua esposa pelo divino amado.

A sua pulsão amorosa, nem sempre correspondida pela castíssima D. Isabel, transfigurou-se muitas vezes na emoção poética que nos legou nas suas cantigas. Nesses momentos é o homem apaixonado, o Trovador e não o rei quem sobe à cena.

ARM: Que aspectos outros julga devam ser analisados e/ou aprofundados em $O$ plantador de naus a haver?

JN: Qualquer obra literária tem uma multiplicidade de aspectos a considerar, tanto mais variados, quantos os leitores e os seus interesses.

No caso da vossa abordagem de O plantador de naus a haver, o inquérito que me foi proposto traduz um levantamento dos mais importantes aspectos da obra. No entanto, há outros que me parecem ter também algum interesse, como por exemplo, a personagem de D. Isabel, que mal foi aflorada nas vossas questões.

Quanto à personagem de D. Dinis - O conflito rei/pai; os conflitos familiares, o conflito com a santidade da esposa.

- Há um outro conflito que eu queria desencadear na peça (tê-lo-ei conseguido?) e que é o conflito do tempo com o tempo, se assim lhe posso chamar. O tempo final de D. Dinis - a sua morte é afinal o seu princípio, pois é uma espécie de ressurreição para um futuro "Morreu o rei D. Dinis/ vai agora a enterrar/ os sonhos do Plantador/ São sementes a romper/ No grito de germinar."

- A estrutura da peça (por estranho que possa parecer, a estrutura é a da Revista à Portuguesa).

- O medievo peninsular ilustrado no percurso de um rei que potenciou o seu apogeu (rituais iniciáticos, divertimento palaciano, as lutas internas pelo poder, o ritual da morte. 
- Um dos objetivos da autora, enunciado na introdução: - Com este texto poesia e História se confundem na metamorfose da palavra em ação. - teria sido conseguido?

\section{ESPAÇO RESERVADO PARA QUALQUER OUTRA MANIFESTAÇ̃̃O DA AUTORA}

Não seria justo dar a entrevista por terminada sem manifestar o meu aplauso ao Professor Dr. Francisco Manuel Silveira pelo seu projeto Autor por Autor, assim como o desejo de sucesso para este projeto que visa ao estudo e à divulgação da dramaturgia portuguesa contemporânea e que, entre os bons frutos que dará, amadurecerá também o fortalecimento dos traços de união entre a cultura portuguesa e a brasileira.

As perguntas que me foram colocadas na entrevista revelam uma leitura muito atenta e sensível de O Plantador de Naus a Haver que está a ser objeto de análise pela Professora Alleid Ribeiro Machado, a quem agradeço o sábio e afetivo empenhamento na abordagem da minha obra.

Licença: $($ ) (1) $\circledast$

Concepção e realização da entrevista:

Alleid Ribeiro Machado

Doutora e mestra egressa do Programa de Pós-Graduação em Literatura Portuguesa da Universidade de São Paulo.

Contato: alleid@alumni.usp.br

(iD : $\underline{\text { https://orcid.org/0000-0001-9359-532X }}$ 